\author{
Maria TYCHANICZ-KWIECIEN' ${ }^{1}$ \\ Marek MARKOWICZ ${ }^{2}$
}

\title{
PROJEKT I BUDOWA STANOWISKA \\ DO WYZNACZANIA WSPÓŁCZYNNIKA \\ PRZEWODZENIA CIEPŁA \\ OTULIN IZOLACYJNYCH
}

\begin{abstract}
Celem pracy był projekt i budowa laboratoryjnego stanowiska pomiarowego do wyznaczania współczynnika przewodzenia ciepła otulin izolacyjnych o pierścieniowym polu przekroju poprzecznego i określonej długości. Jest to szczególnie istotne zagadnienie w przypadku rurociągów ciepłowniczych, gdzie izolacja cieplna odgrywa znaczącą rolę przy poprawnej pracy instalacji. Pomiar współczynnika przewodzenia ciepła otulin izolacyjnych na zbudowanym stanowisku badawczym bazuje na metodzie rurowej, która polega na rozwiązaniu równania różniczkowego ustalonego przewodzenia ciepła w przegrodzie walcowej o nieskończonej długości. Stanowisko zostało wyposażone w dwie sekcje pomiarowe, na których możliwy jest jednoczesny pomiar dwóch różnych próbek badanych izolacji. Wykonano wstępne pomiary cieplne różnych materiałów izolacyjnych na każdej sekcji osobno oraz na obydwu sekcjach uruchomionych jednocześnie. Na podstawie przeprowadzonych pomiarów była możliwa weryfikacja poprawności budowy i działania stanowiska pomiarowego, jak również walidacja zastosowanej metody pomiarowej. Wykonano również pomiary temperatury za pomocą kamery termowizyjnej, dzięki czemu możliwe było ustalenie rozkładu temperatur na sekcjach pomiarowych. Otrzymane wartości współczynnika przewodzenia ciepła badanych materiałów izolacyjnych porównano $\mathrm{z}$ wartościami katalogowymi tych materiałów oraz dokonano analizy możliwych rozbieżności wyników.
\end{abstract}

Słowa kluczowe: izolacja cieplna, współczynnik przewodzenia ciepła, aparat rurowy, pomiary cieplne, badania eksperymentalne

\section{Nomenklatura}

$d$ - średnica badanej otuliny

$L$ - długość badanej otuliny

$\dot{Q}$ - moc cieplna

$\mathrm{T}$ - temperatura

\footnotetext{
1 Autor do korespondencji: Maria Tychanicz-Kwiecień, Politechnika Rzeszowska im. Ignacego Łukasiewicza, al. Powstańców Warszawy 8, 35-959 Rzeszów, e-mail: mtychanicz@prz.edu.pl, ORCID: 0000-0003-4312-2772.

2 Marek Markowicz, Politechnika Rzeszowska im. Ignacego Łukasiewicza, al. Powstańców Warszawy 8, 35-959 Rzeszów.
} 


\section{Symbole greckie}

$\lambda$ - współczynnik przewodzenia ciepła

\section{Indeksy}

1 - dotyczy sekcji 1

2 - dotyczy sekcji 2

Iśr-10śr - dotyczy wartości średniej na termoparach 1-10

$z$ - dotyczy powierzchni zewnętrznej izolacji

w - dotyczy powierzchni wewnętrznej izolacji

\section{Wprowadzenie}

Zastosowanie izolacji cieplnej wynika w głównej mierze z konieczności ograniczenia strat ciepła pomiędzy układem a otoczeniem. Izolacje cieplne są ponadto stosowane od wielu lat w celu poprawy wydajności energetycznej wielu instalacji i urządzeń przemysłowych oraz w celu utrzymania temperatury czynnika na ustalonym poziomie [1]. W związku z tym zakres stosowania izolacji cieplnych jest niezwykle szeroki, począwszy od układów niskotemperaturowych, po budownictwo, ciepłownictwo, systemy grzewcze, wentylacyjne, klimatyzacyjne, energetykę oraz przemysł metalurgiczny i chemiczny.

Istnieje wiele rodzajów izolacji cieplnych zróżnicowanych pod względem struktury wewnętrznej, zakresu temperatur stosowania i wielu innych czynników [2]. Wybór odpowiedniego rodzaju i grubości izolacji jest zależny od wielu kryteriów, w tym wymaganej efektywności cieplnej izolacji, stabilności i jednorodności właściwości cieplnych w czasie oraz zastosowania izolacji [1].

Materiały izolacyjne w znacznej większości posiadają budowę wieloskładnikową i niejednorodną, co wynika $z$ występowania w ich strukturze fazy stałej oraz fazy płynnej. Złożona budowa wewnętrzna izolacji powoduje, że wymiana ciepła zachodząca $w$ tych materiałach jest również bardzo złożona i występuje głównie na drodze przewodzenia ciepła w składniku stałym izolacji. Może występować również konwekcja i promieniowanie cieplne (szczególnie w wysokich temperaturach [3])oraz dyfuzja wilgoci w przypadku izolacji zawilgoconych.

Wśród właściwości cieplnych najbardziej istotnych dla izolacji cieplnych jest współczynnik przewodzenia ciepła. Parametr ten zależy od wielu czynników, w tym od temperatury, ciśnienia, gęstości izolacji, obecności wilgoci, struktury materiału i wielu innych. W przypadku przemysłowych izolacji cieplnych konieczna jest okresowa kontrola właściwości termofizycznych materiałów ze względu na wymaganą stabilność pracy instalacji oraz możliwość starzenia cieplnego izolacji z upływem czasu. Istotne jest, aby warunki pomiaru przewodności cieplnej były zbliżone do warunków, w jakich izolacja będzie docelowo użytkowana. 
Jedyną metodą umożliwiającą prawidłowe określenie wartości współczynnika przewodzenia ciepła dla materiałów izolacyjnych jest metoda doświadczalna [4]. Istnieje wiele doświadczalnych metod pomiaru współczynnika przewodzenia ciepła izolacji [5]. Dobór odpowiedniej metody pomiarowej jest uwarunkowany przede wszystkim rodzajem, kształtem i wymiarami badanej izolacji, dokładnością metody pomiarowej oraz przewidywanym zakresem temperatur.

Ogólnie metody pomiaru współczynnika przewodzenia ciepła materiałów izolacyjnych można podzielić na metody ustalone i nieustalone [6]. Metody ustalone są odpowiednie dla materiałów stosowanych w systemach i instalacjach stałotemperaturowych lub niepodlegających znacznym wahaniom temperatury, jak np. izolacje w systemach grzewczych i rurociągach cieplnych. W przypadku izolacji rurowych pomiar współczynnika przewodzenia ciepła jest wykonywany za pomocą aparatów rurowych, w których próbka badanego materiału ma kształt walcowy. W aparacie rurowym do wyznaczenia przewodności cieplnej określa się moc cieplną przepływającą przez badany materiał oraz różnicę temperatur na powierzchni zewnętrznej i wewnętrznej izolacji o danej długości i średnicy. Współczynnik przewodzenia ciepła wyznacza się z prawa Fouriera dla jedno- lub wielowarstwowej ścianki cylindrycznej. Za pomocą aparatu rurowego można wyznaczyć przewodność cieplną izolacji rurowych stosowanych w systemach grzewczych [7], niskotemperaturowych [8], instalacjach przemysłowych, wodociągowych, sanitarnych, a także izolacji budowlanych [9]. Istnieją również rozwiązania konstrukcyjne oparte na idei aparatu rurowego, umożliwiające pomiar przewodności cieplnej płynów [10], izolacji proszkowych [11] oraz stopów różnych materiałów [12]. Z kolei w [13] przedstawiono budowę mobilnego stanowiska do wyznaczania strat ciepła w rurociągach niskotemperaturowych na podstawie pomiaru właściwości cieplnych różnego rodzaju izolacji. Poszczególne rozwiązania konstrukcyjne aparatów rurowych różnią się pod względem dokładności pomiarów, dlatego istotne jest stosowanie nowoczesnej aparatury pomiarowej w celu uzyskania dokładnych i powtarzalnych wyników.

Celem artykułu jest przedstawienie koncepcji i budowy laboratoryjnego stanowiska pomiarowego służącego do określania współczynnika przewodzenia ciepła otulin izolacyjnych oraz wykonanie wstępnych pomiarów cieplnych. Stanowisko zostało wykonane w Zakładzie Termodynamiki Politechniki Rzeszowskiej w ramach pracy inżynierskiej. Wyposażono je w dwie sekcje pomiarowe, na których umieszczono dwa rodzaje izolacji szeroko wykorzystywanych w instalacjach przemysłowych i systemach grzewczych. Pomiary cieplne przeprowadzono na każdej sekcji oddzielnie oraz na obydwu sekcjach jednocześnie w celu weryfikacji poprawności działania stanowiska. Dodatkowo przeprowadzono pomiary termowizyjne obydwu sekcji w celu ustalenia rozkładu temperatur na powierzchniach zewnętrznych izolacji. Współczynnik przewodzenia ciepła badanych izolacji określono na podstawie rozwiązania równania ustalonego przewodzenia ciepła $w$ jednowarstwowej ściance cylindrycznej. Otrzymane wyniki pomiarów porównano z wartościami przewodności cieplnej deklarowanymi przez producentów oraz przeprowadzono analizę możliwych rozbieżności wyników. 


\section{Przewodzenie ciepła przez jednowarstwową ściankę walcową}

Przyjmuje się założenie, że przepływ ciepła w rurze o nieskończonej długości $L$ i przekroju cylindrycznym jest ustalony w czasie. Temperatura na powierzchni zewnętrznej $T_{w 2} \mathrm{i}$ wewnętrznej $T_{w 1}$ jest stała $\mathrm{i}$ zmienia się jedynie w kierunku promieniowym, co zostało przedstawione na rys. 1. [4].

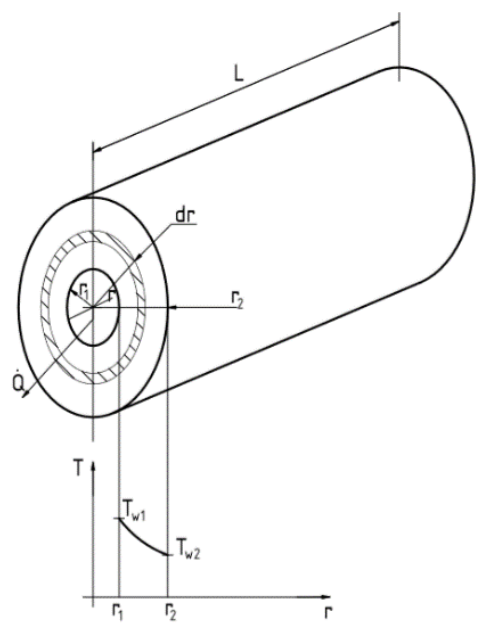

Rys. 1. Przewodzenie ciepła przez ściankę walcową

Gęstość strumienia ciepła zdefiniowana jako:

$$
q=\frac{Q}{A} ; q \neq i d e m
$$

ulega zmianie pomimo stałej mocy cieplnej $\dot{Q}$, ponieważ w kierunku przewodzenia zmienia się powierzchnia wymiany ciepła:

$$
A=2 \pi r L
$$

Zgodnie z prawem Fouriera dla ścianki cylindrycznej o elementarnej grubości $d r$, przewodzona moc cieplna jest wyrażona jako:

$$
\dot{Q}=-\lambda A \frac{d T}{d r}=-2 \pi \lambda L r \frac{d T}{d r}=i d e m
$$

Po wykonaniu operacji rozdzielenia zmiennych i scałkowaniu otrzymuje się średnią wartość współczynnika przewodzenia ciepła $\lambda_{m}$ dla zakresu temperatur od $T_{w 1}$ do $T_{w 2}$ :

$$
\lambda_{m}=\frac{\dot{Q} \ln \left(\frac{r_{2}}{r_{1}}\right)}{\left(T_{W 1}-T_{W 2}\right) 2 \pi L}
$$


Zgodnie z równaniem (4), pomiar przewodności cieplnej za pomocą aparatu rurowego opiera się na pomiarze mocy cieplnej dostarczonej do układu, różnicy temperatur oraz geometrii badanego materiału.

\section{Opis stanowiska pomiarowego}

Na rysunku 2. przedstawiono schemat stanowiska pomiarowego do wyznaczania współczynnika przewodzenia ciepła izolacji rurowych [14], które zostało zbudowane w Zakładzie Termodynamiki Wydziału Budowy Maszyn i Lotnictwa Politechniki Rzeszowskiej w ramach pracy inżynierskiej. Z kolei na rysunku 3. przedstawiono widok rzeczywisty zbudowanego stanowiska pomiarowego. Stanowisko składa się z dwóch sekcji pomiarowych. Zasadniczym elementem każdej z sekcji jest cienkościenna, miedziana rura $\mathrm{z}$ umieszczoną wewnątrz grzałką elektryczną, na której z zewnątrz jest nałożona badana izolacja cieplna. Materiał izolacji musi pozostawać $\mathrm{w}$ bezpośrednim kontakcie $\mathrm{z}$ powierzchnią rury, aby uniknąć termicznych oporów kontaktowych. Grzałki są zasilane z instalacji elektrycznej poprzez autotransformator. Do powierzchni zewnętrznej i wewnętrznej badanych izolacji są przymocowane rezystancyjne czujniki temperatury typu Pt100. Każdej z sekcji odpowiada 5 czujników temperatury: 2 czujniki na powierzchni wewnętrznej badanej izolacji i 3 - na powierzchni zewnętrznej. Czujniki są rozmieszczone w różnych miejscach i umożliwiają uzyskanie średniego rozkładu temperatury na powierzchniach badanych izolacji. Odczyt temperatury z poszczególnych termopar jest możliwy dzięki miernikowi temperatury, do którego podłączony jest przełącznik miejsc pomiarowych.

Stanowisko zostało wyposażone również w pulpit sterowniczy umiejscowiony w specjalnej obudowie przymocowanej do stołu. Na pulpicie sterowniczym można włączyć zasilanie główne oraz danej sekcji, a także dokonywać odczytu temperatur oraz parametrów elektrycznych grzałki. W celu zapewnienia sztywności całej konstrukcji, rurę wraz z izolacją przymocowano w specjalnie zaprojektowanych uchwytach i całość przytwierdzono do stołu. Pomiary na stanowisku badawczym są możliwe po włączeniu zasilania danej sekcji lub obydwu sekcji jednocześnie. Należy obserwować wskazania czujników temperatury do chwili ich ustalenia się. Po osiągnięciu stanu termicznie ustalonego można przystąpić do pomiarów właściwych. W tym celu należy odczytać pięciokrotnie, w około pięciominutowych odstępach czasu moc grzałki oraz temperaturę na każdym z czujników temperatury, odpowiadających danej sekcji pomiarowej. Warto pamiętać, że podczas pomiarów nie należy dokonywać zmian w zasilaniu żadnej z sekcji pomiarowych.

Aby móc obliczyć współczynnik przewodzenia ciepła, należy wyznaczyć średnią temperaturę na powierzchni zewnętrznej i wewnętrznej badanej otuliny:

$$
T_{z 1}=\frac{T_{1 s r}+T_{2 \xi r}+T_{3 \xi r}}{3}
$$




$$
\begin{aligned}
& T_{w 1}=\frac{T_{4 \delta r}+T_{5 \delta r}}{2} \\
& T_{w 2}=\frac{T_{6 s}+T_{7 s} r}{2} \\
& T_{z 2}=\frac{T_{8 \delta r}+T_{9 s r}+T_{10 \delta r}}{3}
\end{aligned}
$$

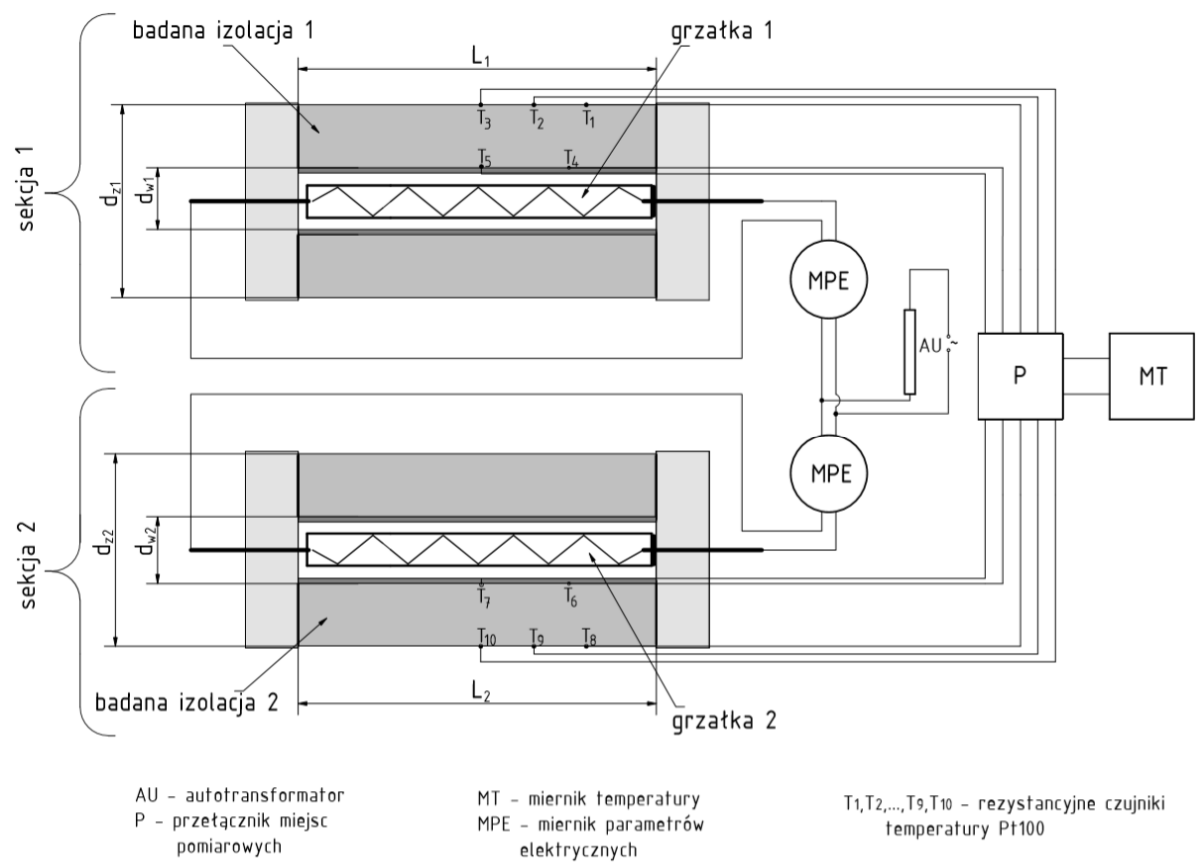

Rys. 2. Schemat stanowiska pomiarowego

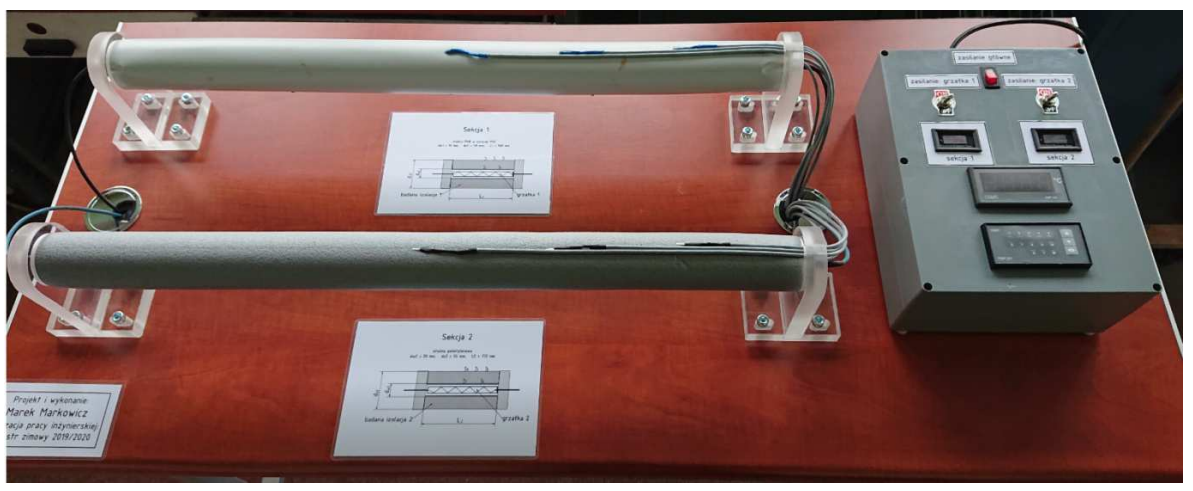

Rys. 3. Widok rzeczywisty stanowiska pomiarowego do pomiaru przewodności cieplnej otulin izolacyjnych 
Wykorzystując średnie wartości temperatur na powierzchniach zewnętrznych i wewnętrznych badanych otulin, należy obliczyć współczynnik przewodności cieplnej badanych izolacji, korzystając ze wzorów:

$$
\begin{aligned}
& \lambda_{1}=\frac{\dot{Q} \ln \left(\frac{d_{z 1}}{d_{w 1}}\right)}{\left(T_{w 1}-T_{z 1}\right) 2 \pi L_{1}} \\
& \lambda_{2}=\frac{\dot{Q} \ln \left(\frac{d_{z 2}}{d_{w 2}}\right)}{\left(T_{w 2}-T_{z 2}\right) 2 \pi L_{2}}
\end{aligned}
$$

\section{Pomiary eksperymentalne}

\subsection{Pomiary na każdej sekcji oddzielnie}

Do pomiarów współczynnika przewodzenia ciepła wybrano następujące materiały izolacyjne:

1. Sekcja 1 - otulina PUR w osłonie PVC o wymiarach:

$d_{w 1}=0,018 \mathrm{~m} ; d_{z 1}=0,059 \mathrm{~m} ; L_{1}=0,769 \mathrm{~m}$

2. Sekcja 2 - otulina polietylenowa o wymiarach:

$$
d_{w 2}=0,020 \mathrm{~m} ; d_{z 2}=0,055 \mathrm{~m} ; L_{2}=0,772 \mathrm{~m}
$$

Wybrane materiały należą do materiałów szeroko wykorzystywanych w rurowych instalacjach grzewczych, przemysłowych, wodociągowych, wodnokanalizacyjnych i sanitarnych. Materiały poddano wstępnym badaniom cieplnym w celu określenia ich współczynnika przewodzenia ciepła. Pomiary przeprowadzono dwukrotnie, na każdej sekcji osobno oraz na obydwu sekcjach jednocześnie.

W celu określenia przewodności cieplnej izolacji umieszczonej na sekcji 1 . włączono zasilanie grzałki 1 , po czym po ustaleniu się temperatur przystąpiono do właściwego pomiaru. Mierzone parametry odczytano pięciokrotnie w pięciominutowych odstępach czasu i uśredniono. Wykorzystując wzory (5) i (6), obliczono średnią temperaturę na powierzchni zewnętrznej i wewnętrznej izolacji, natomiast za pomocą wzoru (9) określono współczynnik przewodzenia ciepła izolacji sekcji 1. Wyniki pomiarów i obliczeń przedstawiono w tab. 1.

Tabela 1. Wyniki pomiarów sekcji 1.

\begin{tabular}{|c|c|c|c|}
\hline$\dot{Q}[\mathrm{~W}]$ & $T_{z 1}[\mathrm{~K}]$ & $T_{w 1}[\mathrm{~K}]$ & $\lambda_{1}[\mathrm{~W} /(\mathrm{mK})]$ \\
\hline 13,83 & 308,32 & 364,25 & 0,061 \\
\hline
\end{tabular}


Następnie wyłączono zasilanie grzałki 1 i włączono zasilanie grzałki 2, oczekując na ustalenie się temperatur, po czym dokonano pomiarów właściwych na sekcji 2. Wykorzystując wzory (7) i (8), obliczono średnią temperaturę na powierzchni zewnętrznej i wewnętrznej izolacji, natomiast za pomocą wzoru (10) określono współczynnik przewodzenia ciepła izolacji sekcji 2. Wyniki pomiarów i obliczeń przedstawiono $\mathrm{w}$ tab. 2.

Tabela 2. Wyniki pomiarów sekcji 2.

\begin{tabular}{|c|c|c|c|}
\hline$\dot{Q}[\mathrm{~W}]$ & $T_{z 2}[\mathrm{~K}]$ & $T_{w 2}[\mathrm{~K}]$ & $\lambda_{2}[\mathrm{~W} /(\mathrm{mK})]$ \\
\hline 14,68 & 303,72 & 357,28 & 0,057 \\
\hline
\end{tabular}

\subsection{Pomiary na obydwu sekcjach jednocześnie}

Pomiary na obydwu sekcjach jednocześnie przeprowadzono po włączeniu zasilania i ustaleniu się temperatur na obydwu sekcjach. Wyniki pomiarów mocy cieplnej oraz temperatur na powierzchniach zewnętrznych i wewnętrznych badanych izolacji, wraz z obliczonymi wartościami współczynnika przewodzenia ciepła zaprezentowano w tab. 3 .

Tabela 3. Wyniki pomiarów na obydwu sekcjach jednocześnie

\begin{tabular}{|c|c|c|c|c|}
\hline Sekcja & $\dot{Q}[\mathrm{~W}]$ & $T_{z}[\mathrm{~K}]$ & $T_{w}[\mathrm{~K}]$ & $\lambda[\mathrm{W} /(\mathrm{mK})]$ \\
\hline 1 & 11,85 & 309,46 & 359,93 & 0,058 \\
\hline 2 & 12,68 & 305,76 & 355,24 & 0,053 \\
\hline
\end{tabular}

\subsection{Pomiary termowizyjne}

Badania termowizyjne przeprowadzono w celu ustalenia rozkładu temperatur na sekcjach pomiarowych oraz bardziej szczegółowego poznania zjawisk cieplnych zachodzących podczas pomiarów. Pomiary termowizyjne mogą również służyć do poprawnej interpretacji wyników kolejnych pomiarów eksperymentalnych wykonywanych na stanowisku. Pomiary kamerą termowizyjną przeprowadzono po włączeniu zasilania obydwu grzałek i po osiągnięciu stanu ustalonego. Jako wynik pomiarów otrzymano termogramy obrazujące rozkład temperatur na sekcjach pomiarowych, co przedstawiono na rys. 4. i 5.

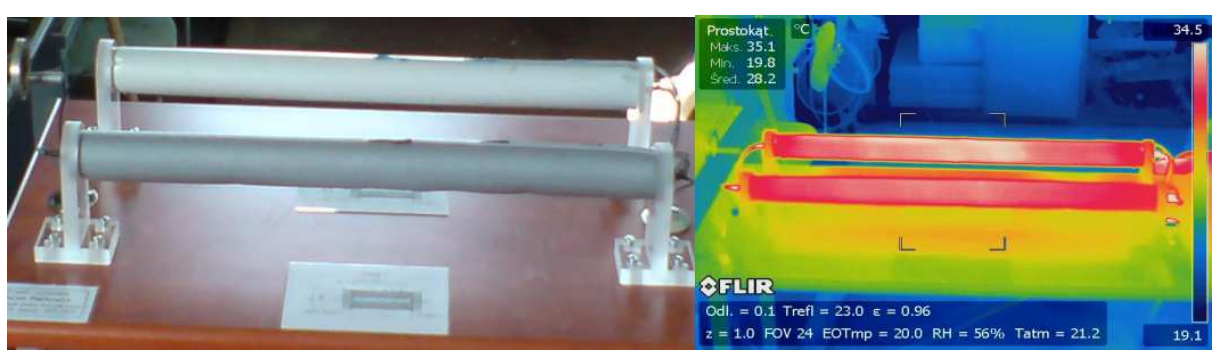

Rys. 4. Rozkład temperatur - sekcje pomiarowe 


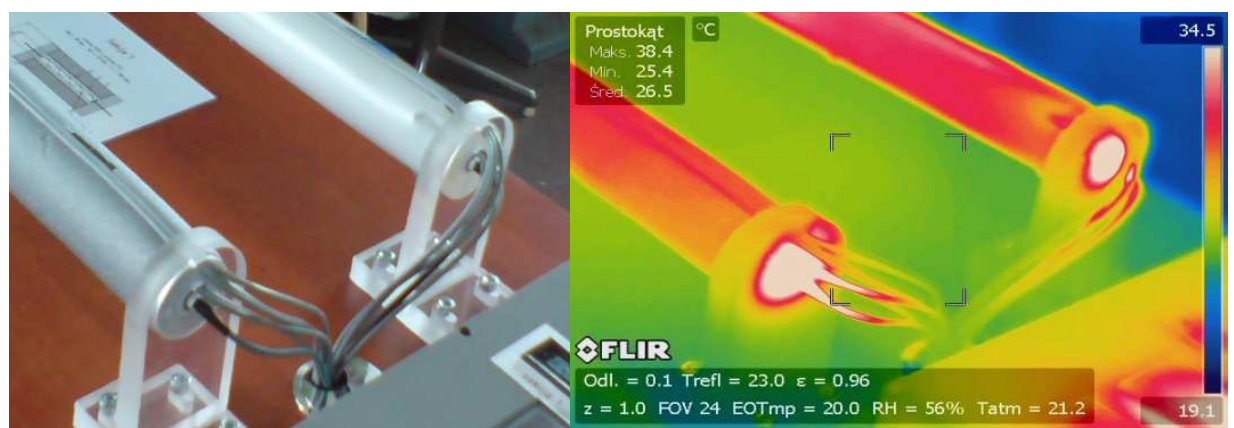

Rys. 5. Rozkład temperatur - powierzchnie czołowe

Na uzyskanych termogramach można zaobserwować wzrost temperatury przy powierzchniach czołowych oraz przewodów zasilających, w wyniku czego część ciepła generowana przez grzałkę jest odprowadzana do otoczenia. Za przyczynę należy uznać brak zastosowania izolacji na powierzchniach czołowych rury, w wyniku czego temperatura izolacji zmniejsza się wraz z oddalaniem się od jej środka i zbliżaniem się do powierzchni czołowych. Innym, bardziej skutecznym rozwiązaniem ograniczającym straty ciepła przez powierzchnie boczne jest zastosowanie grzejników kompensacyjnych, jednak metoda ta jest bardzo pracochłonna ze względu na wymaganą dużą dokładność regulacji ogrzewania kompensacyjnego.

\section{Wnioski}

Otrzymane eksperymentalnie wartości współczynnika przewodzenia ciepła porównano z wartościami deklarowanymi przez producenta, co przedstawiono w tab. 4.

Tabela 4. Porównanie zmierzonej i deklarowanej przewodności cieplnej badanych materiałów izolacyjnych

\begin{tabular}{|l|c|c|}
\hline \multicolumn{1}{|c|}{ Materiał } & PUR w osłonie PVC & Polietylen \\
\hline $\begin{array}{l}\text { Zmierzona przewodność } \\
\text { cieplna na osobnych sekcjach } \\
\lambda[\mathrm{W} /(\mathrm{mK})]\end{array}$ & 0,061 & 0,057 \\
\hline $\begin{array}{l}\text { Zmierzona przewodność } \\
\text { cieplna na obydwu sekcjach } \\
\text { naraz } \lambda[\mathrm{W} /(\mathrm{mK})]\end{array}$ & 0,058 & 0,053 \\
\hline $\begin{array}{l}\text { Deklarowana przewodność } \\
\text { cieplna } \lambda[\mathrm{W} /(\mathrm{mK})]\end{array}$ & $\begin{array}{c}0,035-0,036 \\
\text { dla temperatury ok. } 40^{\circ} \mathrm{C}\end{array}$ & $\leq 0,040$ \\
\hline
\end{tabular}

Można zauważyć, że wartości otrzymane z pomiarów, zarówno indywidualnych, jak i jednoczesnych, różnią się od tych deklarowanych przez producenta. Należy zauważyć, że pomiary eksperymentalne przeprowadzone na stanowisku odbywały się w innych temperaturach niż te, dla których producent określił 
wartości współczynnika przewodzenia ciepła. Za najbardziej prawdopodobną przyczynę rozbieżności można uznać fakt, że na stanowisku pomiarowym użyto rury i izolacji o określonej i skończonej długości (bezwymiarowa długość sekcji 1: $\frac{L_{1}}{d_{z 1}} \cong 13$ oraz sekcji $2: \frac{L_{2}}{d_{z 2}} \cong 14$ ), co powoduje dodatkową wymianę ciepła u powierzchni czołowych. Potwierdzają to zarówno wyniki pomiarów termowizyjnych, jak również rozbieżności wyników pomiarów na każdej z sekcji oddzielnie oraz na obydwu sekcjach jednocześnie. W przypadku pomiarów na każdej z sekcji oddzielnie przez daną grzałkę przepływa prąd o natężeniu większym niż w przypadku zasilania dwóch grzałek jednocześnie, w wyniku czego wydzielana jest większa moc cieplna, a zarazem powstaje większa różnica temperatur między grzałką a otoczeniem. W takim przypadku wzrastają również straty ciepła do otoczenia, co ostatecznie wpływa na wzrost wartości współczynnika przewodzenia. Dodatkowymi źródłami rozbieżności wyników mogą być błędy wynikające z zastosowanej aparatury pomiarowej (czujniki temperatury, mierniki parametrów elektrycznych i inne elementy elektroniczne) oraz błędy pomiaru gabarytów otulin.

Biorąc pod uwagę wyznaczone eksperymentalnie wartości przewodności cieplnej badanych materiałów izolacyjnych oraz wszystkie możliwe rozbieżności w odniesieniu do wartości deklarowanych, można uznać, że stanowisko pomiarowe zostało zbudowane poprawnie, a samą metodę pomiarową za skuteczną do pomiarów walcowych próbek o pierścieniowym polu przekroju poprzecznego.

Planowana jest modyfikacja konstrukcji stanowiska mająca na celu ograniczenie strat ciepła przez powierzchnie czołowe oraz dalsze pomiary eksperymentalne różnych materiałów izolacyjnych.

\section{Literatura}

[1] Furmański P., Wiśniewski T.S., Banaszek J., Izolacje cieplne. Mechanizmy wymiany ciepła, właściwości cieplne i ich pomiary, Instytut Techniki Cieplnej, Politechnika Warszawska, Warszawa 2006.

[2] Górzyński J., Przemysłowe izolacje cieplne, wyd. Sorus, Poznań 1996.

[3] Tychanicz-Kwiecień M., Wilk J., Gil P., Review of High Temperature Thermal Insulation Materials, Journal of Thermophysics and Heat Transfer 33(11):1-13 August 2018.

[4] Kulesza J. i in., Pomiary cieplne - część I: podstawowe pomiary cieplne, Wydawnictwa Naukowo-Techniczne, Warszawa 2001.

[5] Wulf R., Barth G., Gross U., Intercomparison of Insulation Thermal Conductivities Measured by Various Methods, International Journal of Thermophysics (2007) 28:1679-1692.

[6] Yüksel N., The Review of Some Commonly Used Methods and Techniques to Measure the Thermal Conductivity of Insulation Materials, Insulation Materials in Context of Sustainability (2016). 
[7] Zehendner H., Thermal Conductivity of Thermal Insulation Materials on Pipes, Journal of Thermal Insulation, Vol. 7, July 1983.

[8] Cremaschi L., Shanshan C., Worthington K., Ghajar A.J., 2012. Measurements of Pipe Insulation Thermal Conductivity at Below Ambient Temperatures Part I: Experimental Methodology and Dry Tests. ASHRAE Transactions. 118(1):1061-1076.

[9] Carlson J.D., Bhardwaj R., Phelan P.E., Kaloush K.E., Golden J.S., Determining Thermal Conductivity of Paving Materials Using Cylindrical Sample Geometry, Journal of Materials in Civil Engineering 2010.22:186-195.

[10] Iyengar A.S., Abramson A.R., Comparative Radial Heat Flow Method foe Thermal conductivity Measurement of Liquids, Journal of Heat Transfer June 2009, Vol. 131/064502-1.

[11] Flynn D.R., A Radial-Flow Apparatus for Determining the Thermal conductivity of Loose-Fill Insulations to High Temperatures, Journal of Research of the National Bureau of Standards-C. Engineering and Instrumentation, Vol. 67C, No. 2, April-June 1963.

[12] Williams R.K., Radial Heat Flow Thermal Conductivity Apparatus for Measurements on Sulfide and Telluride Melts, The Review of Scientific Instruments, Vol. 39, No. 8 August 1968.

[13] Fesmire J.E. et all, Apparatus and method for thermal performance testing of pipelines and piping systems, United States Patent US 6,715,914 B1, April 2004.

[14] Wesołowski A., Urządzenia chłodnicze i kriogeniczne oraz ich pomiary cieplne, Wydawnictwa Naukowo-Techniczne, Warszawa 1980. 
